\title{
Role of Proangiogenic Tyrosine Kinase with Immunoglobulin and Endothelial Growth Factor Homology Domains 2 Expressing Monocytes in Chronic Lymphocytic
}

\section{Leukemia}

\author{
Amira Raafat Elsheikh ${ }^{1}$, Gehan Abd Elkader ${ }^{2}$, Ahmad Sallam Soliman', Noran Salah Eldin Elsabbagh ${ }^{1}$ \\ Departments of ${ }^{1}$ Clinical Pathology and ${ }^{2}$ Internal Medicine, Faculty of Medicine, Zagazig University, Egypt \\ *Corresponding Author: Noran Salah Eldin Elsabbagh, Email: elsabbaghnoran@gmail.com
}

\begin{abstract}
Background: Globally, highest hematologic malignancy in prevalence is considered chronic lymphocytic leukemia (CLL). The expression of angiopoietin-2 (Ang2) and tyrosine kinase with immunoglobulin and endothelial growth factor homology domains (Tie1), two critical components of the Ang-Tie2 pro-angiogenic pathway, in CLL cells has been demonstrated. Objective: Clarification of Tie2-expressing monocytes' (TEMs) involvement in the pathophysiology of CLL is the goal of this study. Patients and Methods: The study was case control, which was performed on 21 CLL patients; their age ranged from 46 to 71 with a mean of $58.2 \pm 6.9$, in addition to 21 age and sex matched healthy control subjects. Full medical histories, clinical examinations, and laboratory tests were conducted on all individuals. The percentage of TEMs in peripheral blood was determined by flow cytometry and their phenotypic characteristics defined as CD14+/CD16+/Tie-2+ cells. Results: Compared to the control group, there was a statistically significant increase in TEMs in the cases group. Among the cases group there was a statistical significant increase in $\mathrm{LDH}$, uric acid, WBCs, reticulocyte, CD 38 $\beta 2$ microglobulin and TEMS and statistical significant decrease in $\mathrm{Hb}$ with increase Binet stage. There was a statistical significant +ve correlation between TEMs and LDH, WBCs, reticulocytes, CD38 and $\beta 2$ microglobulin. Also, there was a statistical significant negative correlation between TEMs and $\mathrm{Hb}$ and platelets count among the cases group. TEMs percentage had sensitivity, specificity and accuracy (100\%) in diagnosis of leukemia at cut off $>20.95 \%$. Conclusion: TEMs could be a part of CLL pathogenesis which can be a predictor of disease progression alongside with other prognostic indicators.
\end{abstract}

Keywords: Chronic lymphocytic leukemia, Tyrosine kinase with immunoglobulin and endothelial growth factor.

\section{INTRODUCTION}

The most frequent hematologic cancer in Western countries is chronic lymphocytic leukaemia. CLL is an incurable disease, despite recent breakthroughs in treatment. Increased risk of infection, an increased prevalence of autoimmune illnesses, as well as hypogammaglobulinemia are all symptoms of CLL's altered immune system ${ }^{(\mathbf{1})}$.

Clonal proliferation and accumulation of mature monomorphic B lymphocytes (B lymphocytes) in the blood, bone marrow, and the surrounding lymphatic tissues are hallmarks of CLL. They appear to be small, mature lymphocytes that may be combined with large or atypical lymphocytes, or prolymphocytes, in some cases (2).

The majority of circulating human monocytes (90 percent) have strong CD14 but no CD16 expression $\left(\mathrm{CD} 14^{++} \mathrm{CD} 16\right)$, while the minor population is separated into the intermediate subsets $\left(\mathrm{CD} 14^{++} \mathrm{CD} 16^{+}\right.$, and the non-classical subgroup, with high CD16 and low CD14 expression $\left(\mathrm{CD} 14^{+} \mathrm{CD} 16^{++}\right)$are the two groups ${ }^{(3)}$. Furthermore, among circulating monocytes, those that express Tie-2 (angiopoietin receptor tyrosine kinase with immunoglobulin and endothelial growth factor homology domains 2) have tumour-promoting features (4). It was formerly thought that angiopoietin-2 (Ang-2) was a particular ligand for Tie-2 $2^{(5)}$.

Ang-2 from Weibel-Palade bodies activates endothelial cells, which in turn attracts Tie-2-expressing monocytes (TEMs) to the tumour site and stimulates angiogenesis, this process occurs in some circumstances like hypoxia ${ }^{(6)}$. Ang-2 and Tie1 are two key components of the Ang-Tie2 pro-angiogenic pathway in CLL cells. However, the role of the Ang-Tie2 pathway in CLL pathogenesis remains a mystery at this time ${ }^{(7)}$.

By examining Tie2-expressing monocytes (TEMs) in CLL patients, we hoped to better understand their function in the development of the disease.

\section{PATIENTS AND METHODS}

In the Clinical Pathology Department, this case control trial carried out, at Zagazig University Hospitals, between February 2021 and August 2021.

Ethical considerations:

As long as all participants signed informed consent forms and submitted them to Zagazig University's Research Ethics Committee, the study was allowed (ZU-IRB\#6237). We followed the World Medical Association's ethical code for human experimentation, the Helsinki Declaration.

Inclusion criteria: Patients suffering from CLL attending the Oncology Department at Zagazig University Hospital during the study period, and patients were diagnosed as CLL by: Blood tests (CBC and LDH). Bone marrow aspiration and biopsy, and flow cytometry. Exclusion criteria: Patient refusal, and patients with other types of malignancies.

The studied patients were subjected to the following:

This article is an open access article distributed under the terms and conditions of the Creative Commons Attribution (CC BY-SA) license (http://creativecommons.org/licenses/by/4.0/) 
1. Full history taking; complaint, present, past, drug history and history of other malignancy, chemotherapy or radiotherapy.

2. Clinical examination and clinical staging

3. Laboratory investigations including:

- Complete blood count, performed on Sysmex $\mathrm{XN}-2000$ cell counter supplied by (Sysmex, Japan).

- Uric acid, lactate dehydrogenase (LDH) and beta-2-microglobulin performed on Cobas 8000 (Roche Diagnostics, Switzerland).

- Reticulocyte count.

- Anti-CD 38, performed on Becton Dickinson (LA, USA).

Special investigations:

- Immunophenotyping characterization for identification of TEMs using anti-CD14, anti CD-16 and anti-CD202b antibodies by flow cytometry, performed on Becton Dickinson (LA, USA).

\section{Sample collection:}

- Six millimeters of venous blood were collected from each patient under complete aseptic conditions. The collected blood was divided into 3 tubes.

- Two millimeters of PB (What is PB?) were collected into gel activated vacutainers. After clotting of blood samples, centrifugation was done at $2000 \mathrm{rpm}$ for $20 \mathrm{~min}$ and serum was separated and used for measurement of serum level of LDH, uric acid and beta-2microglobulin.

- Two millimeters of PB were collected on ethylenediaminetetraacetic acid (EDTA) solution of Per millilitre of blood, $1.2 \mathrm{mg}$ of the anhydrous salt anhydrous salt for and reticulocyte count and $\mathrm{CBC}$.
- Two millimeters of PB were collected on EDTA solution of for Immunophenotyping, use $1.2 \mathrm{mg}$ of anhydrous salt per $\mathrm{ml}$ of blood.

\section{Flow cytometric Analysis: \\ Principle:}

It is possible to measure numerous physical parameters of a single cell concurrently, such as its size and granularity, as the cell moves through an instrument. Based on the light scattering properties of the cell under research, which may be generated from dyes or monoclonal antibodies (MoAb) targeting either extracellular molecules or intracellular molecules inside the cell, its working is based on this information ${ }^{(8)}$.

\section{Data interpretation:}

From the gated cell population, we calculated the percentage of monocytes positive for the relevant investigated marker. Five percent was chosen as the negative isotopic checkpoint.

\section{Statistical analysis:}

SPSS version 25 was used for statistical analysis. Tables and figures were used to present the data. The mean, standard deviation, range, median, and interquartile range (IQR) of continuous data were shown. Frequencies and proportions were used to represent qualitative data. Two study group means were compared using a Student $\mathrm{T}$ test to determine statistical significance. Correlation data were tested using Pearson's correlation coefficient (r). To measure accuracy, sensitivity and specificity were used to describe it, as well as positive and negative predictive values, and overall accuracy. Qualitative data were analyzed using Pearson's chi square test. $\mathrm{P}$ value of 0.05 or less was considered significant.

\section{Results:}

Splenomegaly and lymphadenopathy were statistically significantly more common in the cases compared to the control group (Table 1).

Table (1): Demographic data and Clinical findings among the studied groups

\begin{tabular}{|c|c|c|c|c|c|c|}
\hline \multicolumn{2}{|c|}{ Variable } & \multirow{2}{*}{\multicolumn{2}{|c|}{$\begin{array}{c}\begin{array}{c}\text { Cases } \\
(\boldsymbol{n}=\mathbf{2 1})\end{array} \\
58.24 \pm 6.97 \\
46-71\end{array}$}} & \multirow{2}{*}{\multicolumn{2}{|c|}{$\begin{array}{c}\begin{array}{c}\text { Control } \\
(\mathbf{n}=\mathbf{2 1})\end{array} \\
56.14 \pm 7.7 \\
42-68\end{array}$}} & \multirow{3}{*}{$\begin{array}{c}\mathbf{P} \\
0.36 \\
\mathbf{P}\end{array}$} \\
\hline Age: (years) & $\begin{array}{l}\text { Mean } \pm S D \\
\text { Range }\end{array}$ & & & & & \\
\hline & & No & $\%$ & No & $\%$ & \\
\hline Sex & $\begin{array}{l}\text { Male } \\
\text { Female }\end{array}$ & $\begin{array}{c}15 \\
6\end{array}$ & $\begin{array}{l}71.4 \\
28.6\end{array}$ & $\begin{array}{c}12 \\
9\end{array}$ & $\begin{array}{l}57.1 \\
42.9\end{array}$ & 0.33 \\
\hline Hepatomegaly & $\begin{array}{l}\text { No } \\
\text { Yes }\end{array}$ & $\begin{array}{c}18 \\
3\end{array}$ & $\begin{array}{l}85.7 \\
14.3\end{array}$ & $\begin{array}{c}21 \\
0\end{array}$ & $\begin{array}{c}100 \\
0\end{array}$ & 0.23 \\
\hline Splenomegaly & $\begin{array}{l}\text { No } \\
\text { Yes }\end{array}$ & $\begin{array}{c}14 \\
7\end{array}$ & $\begin{array}{l}66.7 \\
33.3\end{array}$ & $\begin{array}{c}21 \\
0\end{array}$ & $\begin{array}{c}100 \\
0\end{array}$ & $0.009 *$ \\
\hline Lymphadenopathy & $\begin{array}{l}\text { No } \\
\text { Yes }\end{array}$ & $\begin{array}{c}4 \\
17\end{array}$ & $\begin{array}{l}19 \\
81\end{array}$ & $\begin{array}{c}21 \\
0\end{array}$ & $\begin{array}{c}100 \\
0\end{array}$ & $<0.001 * *$ \\
\hline
\end{tabular}

$*$ : Significant, $* *$ : Highly significant

According to Binet staging, $23.8 \%$ of the studied cases were stage A, $33.3 \%$ were stage B and $42.9 \%$ were stage C. When compared to the control group, there was a statistically significant rise in LDH and WBCs and statistically significant drop in platelets in the cases group (Table 2). 
Table (2): Laboratory findings among the studied groups

\begin{tabular}{|c|c|c|c|c|}
\hline \multicolumn{2}{|c|}{ Variable } & $\begin{array}{l}\text { Cases } \\
(n=21)\end{array}$ & $\begin{array}{c}\text { Control } \\
(n=21)\end{array}$ & P \\
\hline LDH (U/L) & Mean $\pm S D$ & $330.1 \pm 9.69$ & $194.24 \pm 31.98$ & $<0.001 * *$ \\
\hline $\mathrm{UA}(\mathrm{mg} / \mathrm{dl})$ & Mean $\pm S D$ & $5.3 \pm 1.40$ & $4.56 \pm 1.44$ & 0.10 \\
\hline $\mathrm{Hb}(\mathrm{gm} / \mathrm{dl})$ & Mean $\pm S D$ & $10.01 \pm 1.79$ & $13.15 \pm 1.22$ & $<0.001 * *$ \\
\hline Platelets $\left(\mathbf{x 1 0}^{3} / \mathbf{m m}^{3}\right)$ & Mean $\pm S D$ & $161.01 \pm 8.04$ & $252.43 \pm 7.44$ & $<0.001 * *$ \\
\hline WBCs $\left(\times 10^{3} / \mathrm{mm}^{3}\right)$ & Mean $\pm S D$ & $72.65 \pm 7.47$ & $8.08 \pm 1.97$ & $<0.001 * *$ \\
\hline Monocyte (\%) & Mean $\pm S D$ & $6.19 \pm 1.39$ & $5.33 \pm 1.63$ & 0.31 \\
\hline Reticulocytes (\%) & Mean $\pm S D$ & $2.56 \pm 0.12$ & $1.61 \pm 0.49$ & 0.30 \\
\hline
\end{tabular}

**: Highly significant

Compared to the control group, there was a statistically significant increase in Tie2-expressing monocytes in the cases group (Table 3).

Table (3): Tie2-expressing monocytes (TEMs) among the studied groups

\begin{tabular}{|l|l|c|c|c|}
\hline \multicolumn{2}{|c|}{ Variable } & Cases $(\mathbf{n}=\mathbf{2 1})$ & Control $(\mathbf{n}=\mathbf{2 1})$ & $\mathbf{P}$ \\
\hline TEMs (\%) & Mean $\pm S D$ & $62.61 \pm 2.42$ & $8.65 \pm 2.95$ & $<\mathbf{0 . 0 0 1} * *$ \\
& Median $(I Q R)$ & $63.8(40.6-82.85)$ & $7.2(5.25-12.5)$ & \\
\hline
\end{tabular}

**: Highly significant

There was a statistical significant increase in TEMs among cases that had hepatomegaly, splenomegaly and lymphadenopathy compared to cases who hadn't, also there was a statistical significant increase in TEMs level with increase leukemia stage among cases group (Table 4)

Table (4): Relation between Tie2-expressing monocytes (TEMs) and sex and clinical data among the studied cases group

\begin{tabular}{|c|c|c|c|c|c|}
\hline$=$ & & $\mathbf{N}$ & & $(\%)$ & \\
\hline & & & Median & IQR & $\mathbf{P}$ \\
\hline Sex & $\begin{array}{l}\text { Male } \\
\text { Female }\end{array}$ & $\begin{array}{c}15 \\
6\end{array}$ & $\begin{array}{c}72.9 \\
59.55\end{array}$ & $\begin{array}{c}43.9-84.05 \\
34.5-76.1\end{array}$ & $0.35 \mathrm{NS}$ \\
\hline Hepatomegaly & $\begin{array}{l}\text { No } \\
\text { Yes }\end{array}$ & $\begin{array}{c}18 \\
3\end{array}$ & $\begin{array}{c}59.55 \\
87.8\end{array}$ & $\begin{array}{c}39.9-77 \\
75.8-89.75\end{array}$ & $0.04 *$ \\
\hline Splenomegaly & $\begin{array}{l}\mathrm{No} \\
\mathrm{Yes}\end{array}$ & $\begin{array}{c}14 \\
7\end{array}$ & $\begin{array}{l}50.4 \\
83.3\end{array}$ & $\begin{array}{c}34.5-63.8 \\
76.55-89.75\end{array}$ & $0.002 *$ \\
\hline Lymphadenopathy & $\begin{array}{l}\text { No } \\
\text { Yes }\end{array}$ & $\begin{array}{c}4 \\
17\end{array}$ & $\begin{array}{l}33.3 \\
76.1 \\
\end{array}$ & $\begin{array}{c}29-37.2 \\
55.3-83.8 \\
\end{array}$ & 0.005* \\
\hline
\end{tabular}

*: Significant

TEMs and LDH, WBCs, reticulocytes, CD38, and $\beta 2$ microglobin showed a statistically significant positive correlation. Also, there was a statistical significance -ve correlation between TEMs and $\mathrm{Hb}$ and platelets count among the cases group (Table 5).

Table (5): Correlation between Tie2-expressing monocytes (TEMs) and different parameters among the studied groups

\begin{tabular}{|c|c|c|}
\hline \multirow[t]{2}{*}{ Variable } & \multicolumn{2}{|c|}{$\begin{array}{c}\text { TEMs }(\%) \\
(n=30)\end{array}$} \\
\hline & $\mathbf{r}$ & $\mathbf{P}$ \\
\hline Age (years) & 0.11 & $0.63 \mathrm{NS}$ \\
\hline LDH (U/L) & 0.65 & $0.001 *$ \\
\hline UA (mg/dl) & 0.26 & $0.25 \mathrm{NS}$ \\
\hline Hb (gm/dl) & -0.84 & $<0.001 * *$ \\
\hline Platelets $\left(\mathrm{x}^{10} \mathbf{3}^{3} \mathrm{~mm}^{3}\right)$ & -0.31 & 0.04* \\
\hline WBCs $\left(x 10^{3} / \mathrm{mm}^{3}\right)$ & 0.76 & $<0.001 * *$ \\
\hline Monocyte (\%) & 0.05 & $0.85 \mathrm{NS}$ \\
\hline Reticulocytes (\%) & 0.61 & 0.003* \\
\hline CD $38(\%)$ & 0.84 & $<0.001 * *$ \\
\hline ß2 microglobin $(\mathrm{mcg} / \mathrm{ml})$ & 0.78 & $<0.001 * *$ \\
\hline
\end{tabular}

*: Significant, **: Highly significant 
There was a statistical significant increase in LDH, uric acid, WBCs, reticulocyte, CD $38 \beta 2$ microglobulin and TEMs and statistical significant decrease in $\mathrm{Hb}$ with increase disease stage among cases groups (Table 6).

Table (6): Relation between Binet stage and Laboratory findings among the studied cases group.

\begin{tabular}{|c|c|c|c|c|c|}
\hline \multicolumn{2}{|l|}{ Variable } & A $(n=5)$ & B $(n=7)$ & $C(n=9)$ & $\mathbf{P}$ \\
\hline LDH (U/L) & Mean $\pm S D$ & $254 \pm 58.81$ & $301.14 \pm 52.80$ & $394.89 \pm 87.56$ & $0.005 *$ \\
\hline UA (mg/dl) & Mean $\pm S D$ & $4.08 \pm 0.72$ & $5.19 \pm 0.71$ & $6.07 \pm 1.63$ & 0.03* \\
\hline Hb (gm/dl) & Mean $\pm S D$ & $11.9 \pm 0.82$ & $10.83 \pm 0.59$ & $8.33 \pm 1.21$ & $<0.001 * *$ \\
\hline Platelets $\left(\mathrm{x10}^{3} / \mathrm{mm}^{3}\right)$ & Mean $\pm S D$ & $158.29 \pm 27.26$ & $192.28 \pm 5.44$ & $138.21 \pm 9.03$ & $0.08 \mathrm{NS}$ \\
\hline WBCs $\left(x^{10} / \mathbf{m m}^{3}\right)$ & Mean $\pm S D$ & $47.54 \pm 6.3$ & $63.95 \pm 15.14$ & 93.365 .28 & $0.002 *$ \\
\hline Monocyte (\%) & Mean $\pm S D$ & $5.6 \pm 1.29$ & $7 \pm 1.83$ & $5.89 \pm 1.37$ & $0.59 \mathrm{NS}$ \\
\hline Reticulocytes (\%) & Mean $\pm S D$ & $1.48 \pm 0.44$ & $1.39 \pm 0.44$ & $4.07 \pm 0.55$ & 0.008* \\
\hline CD $38(\%)$ & Mean $\pm S D$ & $17.19 \pm 4.22$ & $19.81 \pm 4.72$ & $41.10 \pm 7.60$ & 0.001* \\
\hline B2 microglobulin (mcg/mL) & Mean $\pm S D$ & $1.78 \pm 0.37$ & $1.78 \pm 0.45$ & $2.61 \pm 0.32$ & $<0.001 * *$ \\
\hline TEMs & Mean $\pm S D$ & $32.46 \pm 5.23$ & $56.84 \pm 10.89$ & $83.84 \pm 7.01$ & $<0.001 * *$ \\
\hline
\end{tabular}

*: Significant, $* *$ : Highly significant

TEMs had sensitivity, specificity and accuracy (100\%) in diagnosis of CLL (Table 7).

Table (7): Validity of Tie2-expressing monocytes (TEMs) in diagnosis of CLL among the studied groups.

\begin{tabular}{|l|c|c|c|c|c|c|c|c|}
\hline Marker & Cut off & AUC (95\% CI) & P & Sensitivity & Specificity & PPV & NPV & Accuracy \\
\hline TEMs & $>20.95$ & $1(1)$ & $<0.001 * *$ & $100 \%$ & $100 \%$ & $100 \%$ & $100 \%$ & $100 \%$ \\
\hline
\end{tabular}

\section{DISCUSSION}

In Western countries, chronic lymphocytic leukaemia (CLL), a disease of ageing adults, is the most prevalent adult leukaemia because it generally begins as an indolent condition and many patients survive for a lengthy period of time. A single CD5+ B lymphocyte overgrows and coexpresses modest amounts of surface membrane immunoglobulin ( $\mathrm{smIg}$ ) of a single IG light (L) chain type, as well as, CD20, and CD23, and CD79b (9). Platelet-derived growth factor (PDGF), basic fibroblast growth factor (BFGF), and vascular endothelial growth factor (VEGF), are among the key angiogenic factors secreted by CLL cells. The mechanisms by which most angiogenic factors control CLL cell accumulation and delayed apoptosis remain unknown. There are a number of angiogenic factors, such as angiopoietin-1 (Ang1), leptin, G-CSF, angiogenin (ANG), and midkine that could be used as potential CLL treatment targets in the future ${ }^{(\mathbf{1 0})}$.

Angiogenesis relies heavily on the angiopoietinTie2 pathway. There is evidence that the Ang1-Tie2 axis promotes vessel maturation and vascular integrity, while Tie 2 axis causes vessel neovascularization and regression; this type of monocyte is known as Tie2 expressing monocytes (TEMs) and is linked to the creation of tumour vessels. TEMs have been proven in preclinical investigations to enhance tissue remodelling, and tumour angiogenesis (11).

Ang-2 is produced by CLL cells. Therefore, CLL cells may also have a role in TEM's performance. Ang2 has been shown to influence the production of cytokines by TEMs, such as TNF and IL-12, which have strong antiangiogenic properties. $\mathrm{T}$ cell proliferation and $\mathrm{T}$ cell responsiveness have been reported to be inhibited by TEMs as well, which is essential for controlling cancer ${ }^{(12)}$.

In the present study, on comparing patients' group versus control group, as regards hematological parameters, there was a significant decrease in $\mathrm{Hb}$ level and platelets count with significant increase in TLC and $\mathrm{LDH}$. We found that increased total serum lactate dehydrogenase ( $\mathrm{LDH})$ is generally regarded as indicating high tumour burden or tumour aggressiveness, which is associated with poor prognosis in CLL, as established by AL-Rubaie and Mohammed (13). One of the most commonly elevated serum indicators in CLL (as well as other lymphomas) is associated with a number of unfavourable prognostic features and a greater risk of Richter's syndrome ${ }^{(\mathbf{1 4})}$.

In this study, there was a significantly higher frequency of TEMs among CLL cases compared to healthy subjects. In concordance Woś et al. ${ }^{(12)}$ who reported increased TEMs frequency in CLL patients than the control group. Angiogenesis-promoting M2like phenotype, suppression of T-cell activation, and growth of regulatory T-cells via an IL-10-dependent mechanism are all features of TEM ${ }^{(3)}$.

In the present study CLL patients were classified according to Binet staging into stage A, B and C. On comparing the three stages there were statistical significant differences regarding $\mathrm{Hb}, \mathrm{WBC}, \mathrm{LDH}$, uric acid and reticulocyte count. Li et al. ${ }^{(15)}$ found that individuals with a higher LDH level and lower median haemoglobin level had a more active illness, as evidenced by a more advanced clinical stage, these results are consistent with our results.

Wanchoo et al. ${ }^{(16)}$ revealed that CLL can damage the kidney in a variety of ways, including infiltration, glomerular disease, and electrolyte abnormalities, as 
well as treatment-related toxicities and tumour lysis syndrome.

There are some patients with chronic lymphocytic leukemia who have cytopenia. As a result of CLL, autoimmune hemolytic anaemia is the most prevalent cytopenia. Haemorrhagic necrosis of the blood is characterised by a high reticulocyte count and a positive direct antiglobulin test, as well as elevated serum bilirubin levels ${ }^{(17)}$.

Also, there were statistical significant differences between the three stages regarding CD38, $\quad \beta 2$ microglobulin and TEMs percentage where highest levels were associated with Binet stage $\mathrm{C}$ group. Abdelrahman et al. ${ }^{(18)}$ demonstrated the role of CD38 as a predictor for poor clinical outcome of CLL patients. It functions as a cyclic ADP-ribose that influences mobilization of $\mathrm{Ca}^{2+}$. Consequently, with other factors that could facilitate the homing of CLL cells to tissues with a more favorable environment, which in turn promotes rapid growth and longer survival to leukemic $\beta$ cells in addition to advanced CLL stage.

Patients with CLL who have a high 2microglobulin level are more likely to be in an advanced clinical stage and have a higher tumour burden. A high $\beta 2$ microglobulin (B2M) level in patients with Binet stage $\mathrm{A}$ indicates that $\mathrm{B} 2 \mathrm{M}$ provides extra prognostic information in CLL patients, as demonstrated by the shorter progression-free survival of patients with stage A with low B2M levels ${ }^{(14)}$.

In agreement with the present study Woś et al. ${ }^{(12)}$ and Bojarska-Junak et al. ${ }^{(19)}$ denoted that the Rai stage of the disease had a substantial correlation with the percentage of TEMs in the body. ZAP-70 expression was positively related with the number of TEMs, and greater percentages of TEMs were seen in patients with unfavourable cytogenetic alterations: in individuals with deletion 17p13.1 and/or deletion 11q22.3 compared to those without these abnormalities.

Despite this, Maffei et $\boldsymbol{a l l}^{\left({ }^{(3)}\right.}$ found no correlation between TEM expression and illness stage nor between TEMs number, white blood cell count, or CD38 expression. This may be due to different study populations and different study conditions. The current study also assessed the diagnostic performance of TEMs frequency for diagnosis of CLL patients. Cut off point of $20.95 \%$ with $100 \%$ sensitivity and $100 \%$ specificity was reported. According to Woś et al. ${ }^{(12)}$, TEM low and TEM high patients were separated by a cut off value of 14.82 percent. Patients with TEM low were more likely to be at Rai stage 0 than those with TEM high at the time of their CLL diagnosis.

\section{CONCLUSION}

TEMs could be a part of CLL pathogenesis, which can be a predictor of disease progression alongside with other prognostic indicators.

Financial support and sponsorship: Nil. Conflict of interest: Nil.

\section{REFERENCES}

1. Fiorcari S, Maffei R, Atene C et al. (2021): Nurse-like cells and chronic lymphocytic leukemia B cells: A mutualistic crosstalk inside tissue microenvironments. Cells, 10(2): 217-21.

2. Wierda W, Byrd J, Abramson J et al. (2020): Chronic lymphocytic leukemia/small lymphocytic lymphoma, version 4.2020, NCCN Clinical Practice Guidelines in Oncology. Journal of the National Comprehensive Cancer Network, 18(2): 185-217.

3. Maffei R, Bulgarelli J, Fiorcari S et al. (2013): The monocytic population in chronic lymphocytic leukemia shows altered composition and deregulation of genes involved in phagocytosis and inflammation. Haematologica, 98(7): 1115-1123.

4. Turrini R, Pabois A, Xenarios I et al. (2017): TIE-2 expressing monocytes in human cancers. Oncoimmunology, 6(4): 130-35.

5. Yu X, Ye F (2020): Role of angiopoietins in development of cancer and neoplasia associated with viral infection. Cells, 9(2): 457-62.

6. Cossutta M, Darche M, Carpentier G et al. (2019): Weibelpalade bodies orchestrate pericytes during angiogenesis. Arteriosclerosis, Thrombosis and Vascular Biology, 39(9): 1843-1858.

7. Palma L, Flamme H, Gerke I et al. (2016): Angiopoietins modulate survival, migration, and the components of the AngTie2 pathway of chronic lymphocytic leukaemia (CLL) cells in vitro. Cancer Microenvironment, 9(1): 13-26.

8. Adan A, Alizada G, Kiraz Y et al. (2017): Flow cytometry: basic principles and applications. Critical Reviews in Biotechnology, 37(2): 163-176.

9. Chiorazzi N, Chen S, Rai K (2021): Chronic lymphocytic leukemia. Cold Spring Harbor Perspectives in Medicine, 11(2): 35-41.

10. Palma L, Gehrke I, Kreuzer K (2015): Angiogenic factors in chronic lymphocytic leukaemia (CLL): Where do we stand?. Critical Reviews in Oncology/Hematology, 93(3): 225236.

11. Xue R, Sheng Y, Duan $X$ et al. (2021): Tie2-expressing monocytes as a novel angiogenesis-related cellular biomarker for non-small cell lung cancer. International Journal of Cancer, 148(6): 1519-1528.

12. Woś J, Chocholska S, Kowalska W et al. (2021): Prognostic Value of Tie2-Expressing Monocytes in Chronic Lymphocytic Leukemia Patients. Cancers, 13(11): 2817-2821.

13. AL-Rubaie H, Mohammed S (2018): Assessment of interleukin-8 in patients with chronic lymphocytic leukemia in correlation with the prognostic factors: $\beta 2$-microglobulin, ldh and binet stage. Iraqi Postgraduate Medical Journal, 17(2): 1-4.

14. Rosenquist R, Cortese D, Bhoi S et al. (2013): Prognostic markers and their clinical applicability in chronic lymphocytic leukemia: where do we stand?. Leukemia \& Lymphoma, 54(11): 2351-2364.

15. Li H, Xiong W, Liu H et al. (2017): Serum LDH level may predict outcome of chronic lymphocytic leukemia patients with a 17p deletion: a retrospective analysis of prognostic factors in China. Chinese Journal of Cancer Research, 29(2): 156-165.

16. Wanchoo R, Bernabe C, Barrientos J et al. (2018): Renal involvement in chronic lymphocytic leukemia. Clinical Kidney Journal, 11(5): 670-680.

17. Haider M, Khan S, Shahid S et al. (2019): Autoimmune cytopenias in chronic lymphocytic leukemia. Pakistan Journal of Medical Sciences, 35(5): 1334-1338.

18. Abdelrahman A, Ibrahim M, Hamza M et al. (2018): Relevance of CD49d and CD38 expressions as predictors of disease progression in chronic lymphocytic leukemia. The Egyptian Journal of Haematology, 43(2): 88-91.

19. Bojarska-Junak A, Grundszok $P$, Waldowska $M$ et al. (2016): Tie-2 expressing monocytes in chronic lymphocytic leukemia. Acta Haematologica Polonica, 47(3): 211-218. 